\title{
Electrical and Thermal Behavior of Copper-Epoxy Nanocomposites Prepared via Aqueous to Organic Phase Transfer Technique
}

\author{
N. H. Mohd Hirmizi, ${ }^{1}$ M. Abu Bakar, ${ }^{1}$ W. L. Tan, ${ }^{1}$ N. H. H. Abu Bakar, ${ }^{1}$ \\ J. Ismail, ${ }^{1}$ and C. H. See ${ }^{2,3}$ \\ ${ }^{1}$ Nanoscience Research Laboratory, School of Chemical Sciences, Universiti Sains Malaysia, 11800 Penang, Malaysia \\ ${ }^{2}$ Intel Technology (M) Sdn Bhd, Bayan Lepas FTZ, Phase III, 11900 Penang, Malaysia \\ ${ }^{3}$ BCI Chemical Corporation Sdn Bhd, Lot 7, Jalan BS 7/22, Taman Perindustrian Bukit Serdang, Seksyen 7, \\ 43300 Sri Kembangan, Malaysia
}

Correspondence should be addressed to M. Abu Bakar, bmohamad@usm.my

Received 31 October 2011; Accepted 19 December 2011

Academic Editor: Sevan P. Davtyan

Copyright (C) 2012 N. H. Mohd Hirmizi et al. This is an open access article distributed under the Creative Commons Attribution License, which permits unrestricted use, distribution, and reproduction in any medium, provided the original work is properly cited.

The preparation, electrical, and thermal behaviors of copper-epoxy nanocomposites are described. Cetyltrimethylammonium bromide- (CTAB-) stabilized copper $(\mathrm{Cu})$ particles were synthesized via phase transfer technique. Isopropanol (IPA), sodium borohydride $\left(\mathrm{NaBH}_{4}\right)$, and toluene solution of diglycidyl ether of bisphenol A (DGEBA) were used as transferring, reducing agent, and the organic phase, respectively. The UV-Vis absorbance spectra of all the sols prepared indicate that the presence of Cu particles with the particles transfer efficiency is $\geq 97 \%$. The amount, size, and size distribution of particles in the organosol were dependent on the content of organic solute in the organosol. The composites were obtained upon drying the organosols and these were then subjected to further studies on the curing, thermal, and electrical characteristic. The presence of Cu fillers does not significantly affect the completeness of the composite curing process and only slightly reduce the thermal stability of the composites that is $>300^{\circ} \mathrm{C}$. The highest conductivity value of the composites obtained is $3.06 \times 10^{-2} \mathrm{~S} \mathrm{~cm}^{-1}$.

\section{Introduction}

Epoxy resin is one of the most used polymers in manufacturing industry. Epoxy contains glycidyl groups that can be cured to form usable materials. It provides good chemical, moisture, and solvent resistance as well as good balance in mechanical and thermal properties [1]. The various uses of epoxy include structural adhesives, construction materials, surface laminates and coatings, and high-performance composite materials $[1,2]$. Epoxy is also extensively applied in electronic packaging. One of the many forms of epoxy employed in electronic packaging is as conducting adhesives. Here, metal fillers are incorporated into the epoxy. However, these are limited to certain metals, namely, Ag [3-6], Au [7], $\mathrm{Ni}[8], \mathrm{Al}[9]$, and $\mathrm{Cu}[10,11]$. The conductivity of $\mathrm{Cu}$ is comparable when compared to $\mathrm{Ag}$ and it is more cost-effective [10]. Even so, preventing these $\mathrm{Cu}$ particles oxidation and coalescence is a synthesis challenge. This, however, can be overcome by incorporation of the particles into a polymer matrix $[10,11]$.

In previous reported studies on the electrical and thermal properties of inorganic-polymer composites $[3,12,13]$, several issues were raised which include the dispersion, size, and shape of fillers in polymer matrices as well as the fillermatrix interaction. Highly dispersed nanosized metal filler within a polymer matrix often exerts unique electrical, thermal, and optical properties. However, highly dispersed particles within a polymer matrix are seldom realized via conventional methods. The typical methods employed in order to enhance the filler dispersion in the polymer matrix include among others reverse micelle [3], chemical vapor condensation [4], ball-milling [5], sol-gel [6], and simultaneous 
visible light photoinduced electron transfer and cationic polymerization process [14]. Recently, Chan et al. [10] have reported on an improved dispersion of commercially obtained nanosized $(<100 \mathrm{~nm})$ Cu particles in epoxy matrix via ultrasonication.

One of the approaches to enhance metal filler dispersion within a polymer is through colloidal formation. Metal hydrosols are easily prepared. However, a majority of known polymers are insoluble in aqueous phase. Thus by employing the aqueous to organic phase metal particles transfer technique [15-18], metal-polymer organosols can be prepared. The resultant metal-polymer organosol afforded respective composites upon drying. The aforementioned technique is deemed suitable for various applications such as in electronic packaging as the synthesized $\mathrm{Cu}$ particles are often in the nanosize regime, has uniform morphology, and is well dispersed within the polymer composite.

In this paper we report a simple and efficient method for the synthesis of $\mathrm{Cu}$ nanoparticles which may be helpful in the large-scale production of $\mathrm{Cu}$ nanoparticles which is applicable in electronic packaging as an alternative or substitute to the currently employed Ag-epoxy composites. The synthesis of $\mathrm{Cu}$ nanoparticles in epoxy is via the aqueous to organic phase transfer technique. The epoxy was dissolved in toluene and used as the organic media. The $\mathrm{Cu}^{2+}$ ions in aqueous phase are stabilized by cetyltrimethylammonium bromide, $\mathrm{CTAB}$, and are reduced to metal particles using a strong reducing agent, sodium borohydride, $\mathrm{NaBH}_{4}$. Isopropanol, IPA, is used as an aqueous to organic phase transferring agent for the $\mathrm{Cu}$ particles. The final composites were obtained upon curing the $\mathrm{Cu}$-epoxy with $4,4^{\prime}$-methylenedianiline, MDA. The characteristic of cured samples and thermal and electrical behavior of the composites is evaluated and discussed.

\section{Experimental}

2.1. Materials. Cupric acetate $\left(\left(\mathrm{CH}_{3} \mathrm{COO}\right)_{2} \mathrm{Cu} \cdot \mathrm{H}_{2} \mathrm{O}, 98.0 \%\right)$ was obtained from BDH Chemicals Ltd, England. The cationic surfactant cetyltrimethylammonium bromide, $\mathrm{CTAB}$ $\left(\mathrm{C}_{19} \mathrm{H}_{42} \mathrm{NBr}\right.$, 99\%), and isopropanol, IPA $\left(\left(\mathrm{CH}_{3}\right)_{2} \mathrm{CHOH}\right.$, 99.7\%) were obtained from Merck, Germany, and Systerm, Malaysia, respectively. Sodium borohydride $\left(\mathrm{NaBH}_{4}, 95.0 \%\right)$ was purchased from Riedel-de-Haen, toluene $\left(\mathrm{C}_{6} \mathrm{H}_{5} \mathrm{CH}_{3}\right.$, 99.0\%) from R\&M Chemicals, UK, epoxy resin, diglycidyl ether of bisphenol A, DGEBA (DER 331), was from Dow Plastic (M) Sdn Bhd, and 4,4'-methylenedianiline, MDA $\left(\mathrm{CH}_{2}\left(\mathrm{C}_{6} \mathrm{H}_{4} \mathrm{NH}_{2}\right)_{2}, 97.0 \%\right)$, was purchased from Fluka, Japan. All chemicals were used without further purification.

2.2. Synthesis of Copper Sols. Epoxy-stabilized Cu nanoparticles were prepared via the aqueous to organic phase transfer technique. The ratio of aqueous to organic solvent was fixed at 1 to $1(\mathrm{v} / \mathrm{v})$.

In a typical preparation, $2 \mathrm{~mL}$ of $7.95 \times 10^{-2} \mathrm{M} \mathrm{CTAB}$ and $0.5 \mathrm{~mL}$ of an aqueous solution of $0.05 \mathrm{M}$ cupric acetate were mixed under vigorous stirring. This was followed by addition of $5 \mathrm{~mL}$ IPA. Then, $2 \mathrm{~mL}$ of freshly prepared cold $0.02 \mathrm{M} \mathrm{NaBH}_{4}$ was added dropwise into the previous solution. A change in the color of the hydrosol was observed, that is, from very light blue to yellow to dark brown, depending on the amount of $\mathrm{NaBH}_{4}$ added. The molar ratio of $\mathrm{NaBH}_{4}$ to $\mathrm{Cu}^{2+}$ was kept at $\approx 5$ to ensure complete reduction of $\mathrm{Cu}^{2+}$ to zero-valent state.

The organic phase was then added to the $\mathrm{Cu}$ hydrosol obtained previously. The mixture was stirred vigorously for 15 seconds using a magnetic stirrer and then left standing to enable phase separation. Phase separation afforded two layers of which the bottom aqueous layer was stripped of the distinctive color. The upper organic layer now contained the transferred $\mathrm{Cu}$ particles (organosol) with the newly adopted color.

2.3. Preparation of Cured Cu-Epoxy Composites. The organosol, obtained in Section 2.2, was separated and subsequently evaporated using a rotary evaporator at $70^{\circ} \mathrm{C}$ until the toluene was evaporated. Then $0.25 \mathrm{~mol}$ equivalent of MDA (4 mol epoxy requires $1 \mathrm{~mol} \mathrm{MDA}$ ) was added while vigorously stirring. The mixture was stripped off solvent to give a viscous material. This was then placed into a mould and precured in an oven at $80^{\circ} \mathrm{C}$ for 1 hour and then at $150^{\circ} \mathrm{C}$ for 4 hours for curing purposes.

2.4. Characterizations. The presence of $\mathrm{Cu}$ nanoparticles in the respective sols was monitored using a U-2000 Hitachi UV-Vis Spectrophotometer over the wavelength range of 200-1100 nm at room temperature. Distilled water and toluene were used as the reference for aqueous and organic phase, respectively. The samples were placed in a $1 \times 1 \times 4 \mathrm{~cm}$ rectangular cuvette. The morphology of $\mathrm{Cu}$ nanoparticles formed was examined using a Philips CM12 Transmission Electron Microscope (TEM). The TEM samples were prepared by placing 2 to 3 drops of freshly prepared sol onto a 400 mesh carbon-coated copper grid and dried in air at ambient temperature. Particle sizes and the histograms of size distribution were obtained using the Microsoft Excel, based on the diameter of $\geq 400$ particles obtained from the TEM micrographs using the "analySis Docu" Version 3.2 (Soft Imaging System GmbH, Munster, Germany) image analysis computer software. The interactions between the stabilizer, curing agent, and resultant $\mathrm{Cu}$ nanoparticles were examined using a Perkin Elmer, Fourier Transform Infrared (FTIR) model 2000-FTIR, from 4000 to $400 \mathrm{~cm}^{-1}$ employing a very thin layer of sample on a $25 \times 4 \mathrm{~mm}$ KRS- 5 disc. The metal contents in the sols before and after phase transfer were determined using a Perkin Elmer Analyst 100 Atomic Absorption Spectrometer (AAS). The AAS samples were prepared by digesting $1 \mathrm{~mL}$ of the sol aliquot with 3 to 5 drops of aqua-regia. Each sample was prepared in triplicate. The digested solution was diluted to $25 \mathrm{~mL}$ with distilled water prior to analysis.

The glass transition temperature, $T_{g}$, of the samples was determined using a Perkin-Elmer Pyris-6 Differential Scanning Calorimeter (DSC) under nitrogen atmosphere. First, the sample was heated from $-50^{\circ} \mathrm{C}$ to $200^{\circ} \mathrm{C}$ at a heating rate of $20^{\circ} \mathrm{C} \mathrm{min}^{-1}$ and held at $200^{\circ} \mathrm{C}$ for 3 minutes (first scan). Then it was quenched to $-50^{\circ} \mathrm{C}$ and held for 3 minutes. 
After that, it was reheated for second scan from $-50^{\circ} \mathrm{C}$ to $200^{\circ} \mathrm{C}$ at a heating rate of $20^{\circ} \mathrm{C} \mathrm{min}^{-1}$. Thermogravimetry Analysis (TGA) was performed on $851^{\mathrm{e}}$ Mettler Toledo TGA/ SDTA to study the thermal stability of composites. Linear Coefficient of Thermal Expansion (CTE), $\alpha$, of unfilled and filled cured epoxy was measured using a Perkin-Elmer Pyris Diamond Thermal Mechanical Analyzer (TMA) in expansion mode. Cylinder-shaped samples, with a cross-sectional area of $5 \mathrm{~mm}^{2}$ and length of $8 \mathrm{~mm}$, were used. Samples were heated from room temperature to $180^{\circ} \mathrm{C}$ at a heating rate of $5^{\circ} \mathrm{C} \mathrm{min}^{-1}$. Two heating scans were performed. The first was to eliminate any internal stress and moisture in the sample that may arise during curing and sample preparation processes. The second heating scan was employed to determine the CTE of the material. Each measurement was performed in duplicate.

The electrical resistivity $(\rho)$ measurements were carried out using two methods. The 4-point probe technique was employed for samples of low resistivity value by using Changmin Tech CMT-SR2000N equipment. All of the four probes pointed towards the surface of the samples. The samples were cast as a thin film on a $1.0 \times 1.0 \mathrm{~cm}$ glass slide. For samples of high resistivity value, however, the $I$ $V$ curves were obtained via 2-point probe technique using a Keithly Model $82 \mathrm{CV}-\mathrm{IV}$ Measurement System over the applied voltage ranging from $-100 \mathrm{~V}$ to $+100 \mathrm{~V}$ and a scan rate of $50 \mathrm{~Hz}$. The first probe pointed towards the surface of the sample while the other probe was connected to the stage of the sample holder. The samples were cast as a thin film on an aluminium foil. For the electrical conductivity studies, the following volume fraction of $\mathrm{Cu}$ filler was used: 0.1 vol.\%, 0.5 vol. $\%, 1.0$ vol. $\%, 3.0$ vol. $\%$, and 5.0 vol. $\%$. The sample thickness was measured using a Mitutoyo micrometer, with a resolution of $1 \mu \mathrm{m}$. For each sample, at least 5 locations were identified for the purpose of measurement. The sample resistivity was calculated using $(1)[4,6]$. The conductivity $(\sigma)$ of thus-prepared $\mathrm{Cu}$-epoxy/MDA nanocomposites was then calculated using (2):

$$
\begin{gathered}
\rho=\frac{R A}{t}, \\
\sigma=\frac{1}{\rho} .
\end{gathered}
$$

In (1), $R$ is the resistance, $A$ is the cross-sectional area and $t$ is the thickness of the sample.

\section{Results and Discussion}

\subsection{Copper Sols}

3.1.1. Synthesis. CTAB-stabilized $\mathrm{Cu}$ nanoparticles were first prepared in aqueous phase by reducing copper acetate with $\mathrm{NaBH}_{4}$ in the presence of CTAB. According to Liz-Marzán and Philipse [19], the reduction of metal salts by borohydride in aqueous solution occurs via either (3) or (4). Thus regardless of the ratio of copper salt to borohydride used, a brownish $\mathrm{Cu}$ hydrosol is obtained:

$$
\begin{aligned}
& 2 \mathrm{Cu}^{2+}+\mathrm{BH}_{4}^{-}+3 \mathrm{H}_{2} \mathrm{O} \longrightarrow 2 \mathrm{Cu}^{0}+\mathrm{H}_{2} \mathrm{BO}_{3}^{-}+4 \mathrm{H}^{+}+2 \mathrm{H}_{2}, \\
& 4 \mathrm{Cu}^{2+}+\mathrm{BH}_{4}^{-}+3 \mathrm{H}_{2} \mathrm{O} \longrightarrow 4 \mathrm{Cu}^{0}+\mathrm{H}_{2} \mathrm{BO}_{3}^{-}+8 \mathrm{H}^{+} .
\end{aligned}
$$

In the hydrosol, the $\mathrm{Cu}$ particles are stabilized by a bilayer structure of CTAB that inhibits particle agglomerations via steric repulsion [20, 21]. Addition of toluene to the hydrosol followed by vigorous stirring generates an emulsion. This causes the destruction of the CTAB bilayer to a monolayer with preferential outward orientation of the hydrophobic ends of CTAB, thus creating a shell that favors the organic phase. This phenomenon promotes monolayer $\mathrm{CTAB}$-stabilized $\mathrm{Cu}$ particles to be transported to the organic phase. The aqueous to organic phase transportation of these stabilized Cu particles is assisted by IPA which acts as a transferring agent. IPA acts as an intermediate medium between the aqueous and organic phase that in turn facilitates particles transfer [22]. Upon phase separation, the aqueous phase becomes colorless while the organic phase turns brown. This indicates the presence of $\mathrm{Cu}$ particles in the organic phase. A similar but more intense color of organic phase is observed when the organic phase contains epoxy. This may signify the existence of a higher amount of $\mathrm{Cu}$ particles compared to the organic phase comprising solely of toluene.

The amount of $\mathrm{Cu}$ in aqueous and organic phase after particle phase transfer is tabulated in Table 1. After phase transfer, there is $\leq 5 \%$ of $\mathrm{Cu}$ left in the aqueous phase. Thus overall $\mathrm{Cu}$ particle transfer efficiency from aqueous to the organic phase is high. However, it is interesting to note that when particles are transferred into solely toluene, the organic phase is rendered unstable. Toluene is only able to stabilize $\approx 30 \%$ of the transferred $\mathrm{Cu}$ particles with the rest $(\approx 60 \%)$ being precipitated at the aqueous-toluene interface. When the organic phase consists of $10 \% \mathrm{v} / \mathrm{v}$ of epoxy in toluene, the particle stabilization is increased as compared to neat toluene. This suggests an increase in the amount of $\mathrm{Cu}$ particles in the organic phase but a decrease both in aqueous phase and at the aqueous-organic interface. Thus epoxy stabilizes the $\mathrm{Cu}$ particles in the organic phase.

3.1.2. Characterization. UV-Vis absorbance spectra of $\mathrm{Cu}$ sols are shown in Figure 1. $\lambda_{\max }$ and maximum absorbance (Abs) of the various sols are tabulated in Table 1. Cu hydrosol exhibits a $\lambda_{\max }$ at $425 \mathrm{~nm}$ while the organosols comprise toluene at $495 \mathrm{~nm}$ and epoxy-toluene at $500 \mathrm{~nm}$. Therefore a red shift is observed in $\lambda_{\max }$ values, that is, from aqueous to toluene and to epoxy-toluene. In this work, no characteristic absorbance attributed to $\mathrm{Cu}^{2+}$ ions at around $800 \mathrm{~nm} \mathrm{[23]} \mathrm{or}$ the intermediate copper oxides that is $\mathrm{CuO}\left(\lambda_{\max }=390 \mathrm{~nm}\right)$ and $\mathrm{Cu}_{2} \mathrm{O}\left(\lambda_{\max }=501 \mathrm{~nm}\right)[24]$ are observed. Therefore the $\mathrm{Cu}^{2+}$ ions have been reduced to metallic $\mathrm{Cu}$ and that $\mathrm{NaBH}_{4}$ reduction of copper acetate in aqueous CTAB solution is a clean reaction.

The observed red shift in the $\lambda_{\max }$ from aqueous to organic phase can be attributed to the different environment 
TABLE 1: Cu particles in various phases after phase transfer and $\lambda_{\max }$ (Abs) of UV-Vis spectra and average particle size of the respective samples.

\begin{tabular}{|c|c|c|c|c|c|c|}
\hline \multirow{2}{*}{ Phase } & \multirow{2}{*}{$\begin{array}{c}\text { Transfer Efficiency } \\
(\%)\end{array}$} & \multicolumn{3}{|c|}{ Amount of Particles (\%) } & \multirow{2}{*}{$\lambda_{\max },(\mathrm{nm})(\mathrm{Abs})$} & \multirow{2}{*}{ Average Size (nm) } \\
\hline & & $\begin{array}{l}\text { Aqueous } \\
\text { Phase }\end{array}$ & $\begin{array}{c}\text { Interface } \\
\text { (precipitate) }\end{array}$ & $\begin{array}{l}\text { Organic Phase } \\
\text { (filler loading) }\end{array}$ & & \\
\hline Hydrosol & - & - & - & - & $425(2.59)$ & $4.4 \pm 1.2$ \\
\hline Toluene & 94.9 & 5.1 & 62.6 & 32.3 & $495(3.01)$ & $8.6 \pm 2.8$ \\
\hline $10 \%(\mathrm{v} / \mathrm{v})$ epoxy-toluene & 97.2 & 2.8 & 52.5 & $44.7(0.05)$ & $500(3.20)$ & $4.6 \pm 1.1$ \\
\hline
\end{tabular}

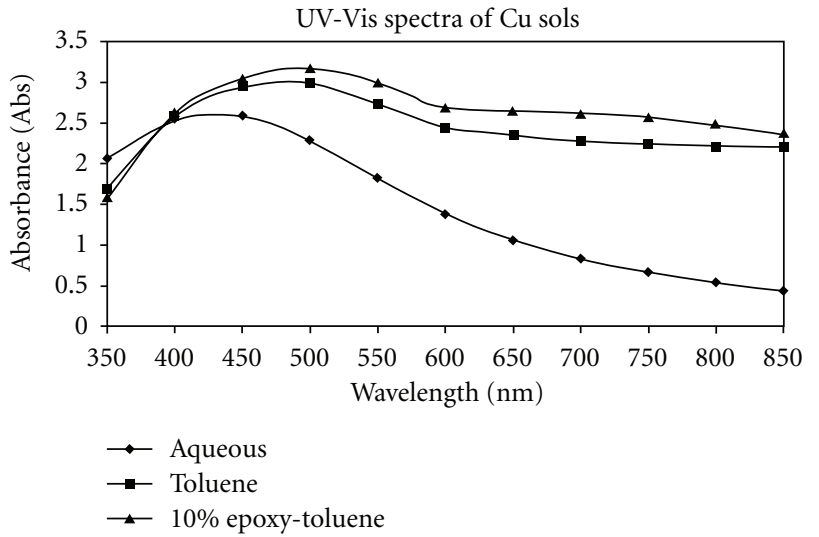

Figure 1: UV-Vis absorbance spectra of (a) Cu hydrosol (prior to phase transfer) and organosols (after phase transfer), that is, (b) toluene, and (c) 10\% epoxy-toluene.

that is the matrix which surrounds these particles as well as the obtained size and shape of $\mathrm{Cu}$ particles. Upon particles transfer from aqueous to organic phase, an increase in refractive index of the medium, that is, transition from water (refractive index, $n=1.33)$ to toluene $(n=1.49)$ occurs. This phenomenon may have caused the observed red shift in the $\lambda_{\max }$. Similar occurrences have been seen by other workers $[25,26]$. For example, a study by Gao et al. [25] on water to toluene phase transfer of silver nanoparticles showed a red shift from $378 \mathrm{~nm}$ to $405 \mathrm{~nm}$. Underwood and Mulvaney [26] also reported changes in optical properties of colloidal gold as a function of the refractive index of the medium. Meanwhile, Jana et al. [27] have reported that hydrosol comprising of uncapped spherical $\mathrm{Cu}$ particles synthesized via $\mathrm{NaBH}_{4}$ reduction of $\mathrm{CuSO}_{4}$ exhibits a $\lambda_{\max }$ at $500 \mathrm{~nm}$. The $\lambda_{\max }$ of hydrosols comprising of spherical glucose-stabilized $\mathrm{Cu}$ particles with an average size of $\approx 4 \mathrm{~nm}$ and $\approx 20 \mathrm{~nm}$ are $463 \mathrm{~nm}$ and $499 \mathrm{~nm}$, respectively [28]. These clearly demonstrate how various factors influence the position of the $\lambda_{\max }$.

In order to ascertain the effect of size and shape of $\mathrm{Cu}$ particles to the position of $\lambda_{\max }$, TEM analysis was carried out. TEM images (at low and high magnification) and size distribution histograms of $\mathrm{Cu}$ particles in aqueous and various organic phases are shown in Figure 2. From the images, the shape of the particles is generally spherical and reveals the existence of interparticle networks. The spacing between neighbouring particles is at around $5 \mathrm{~nm}$. It is expected that these interparticle networks may provide possible routes for conduction either thermal or electrical within the nanocomposites. Average particle sizes of various $\mathrm{Cu}$ sols as derived from the TEM images are tabulated in Table 1. Comparison of the average particle size of $\mathrm{Cu}$ sols shows that average size increased from $4.4 \pm 1.2 \mathrm{~nm}$ to $8.6 \pm 2.8 \mathrm{~nm}$ upon transfer from aqueous to toluene phase. However, addition of epoxy to $\mathrm{Cu}$ organosol does not affect the average particle size significantly. Here, the average particle size increases slightly as compared to the hydrosol to $4.6 \pm 1.1 \mathrm{~nm}$. In this case the shift may have been caused by the different environment instead of the particle size. From TEM analysis, the trend of particle size does not correlate well with the position of $\lambda_{\max }$. Thus, in our case, the different environment is the dominant factor as compared to the size and shape of particles.

The variation in the average particle size of $\mathrm{Cu}$ sols can be explained based on the stabilization effect of CTAB. As discussed before, in hydrosol, $\mathrm{Cu}$ particles are protected by $\mathrm{CTAB}$ bilayers as compared to monolayers in organosol. Thus there is a change in surface potential of nanoparticles in transient from aqueous to organic environment due the thinner protective CTAB layer that caused the particles to further grow. Nevertheless, CTAB still establishes control on the consequent shape of the particles. Therefore the spherical shape of the particle is maintained. In epoxy, however, the size of the particles is also maintained. These particles are surrounded and trapped within the voids of the epoxy interchain networks and/or through certain interactions with the epoxide functional groups. In order to ascertain the latter, FTIR analysis was carried out. This is shown in Figure 3. No change in the functional groups positions is observed. This verifies that there is no chemical interaction between the $\mathrm{Cu}$ particles and the epoxy. Thus, in epoxy-toluene organosols, stabilization of particles is via physical trapping within the epoxy matrix. Besides that, those voids could also pose as a filtering medium whereby only finer particles are able to cross from aqueous to organic interphase boundary and accommodated within polymer inter-chain networks. The oversized particles are excluded and these settled at the aqueous-organic interface as observed. This phenomenon may also be one of the reasons for the size maintaining of $\mathrm{Cu}$ particles.

\subsection{Cu-Epoxy Composites}

3.2.1. Effect of Curing. FTIR spectra of neat epoxy, MDA, cured epoxy/MDA (cured epoxy), and cured Cu-epoxy/MDA (cured composite) are shown in Figure 4. For neat epoxy, 

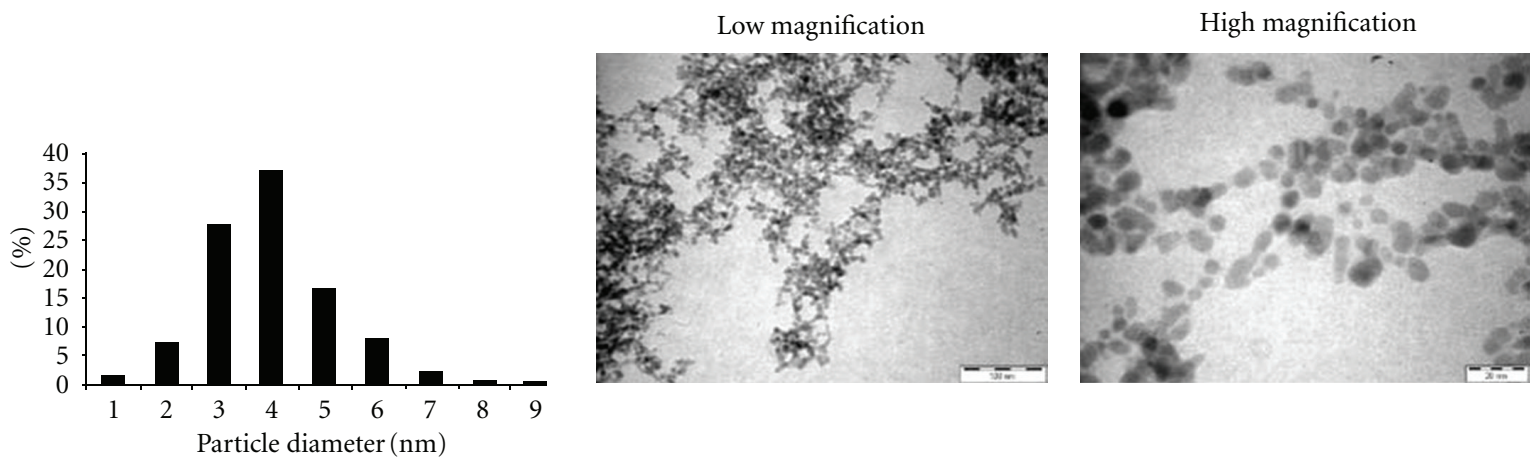

(a) $d=4.4 \pm 1.2 \mathrm{~nm}$
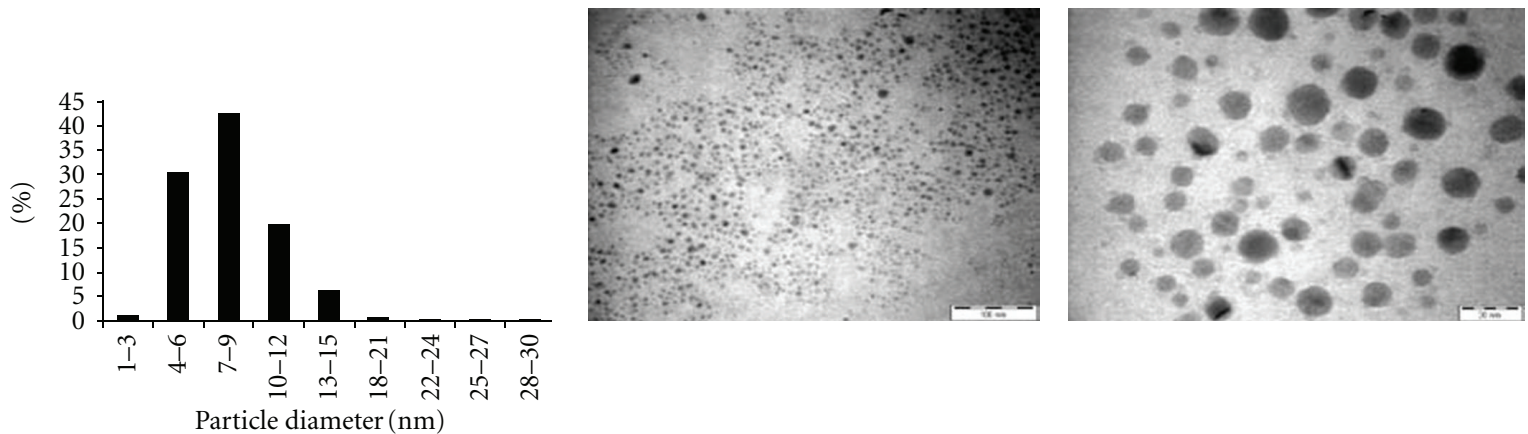

(b) $d=8.6 \pm 2.8 \mathrm{~nm}$

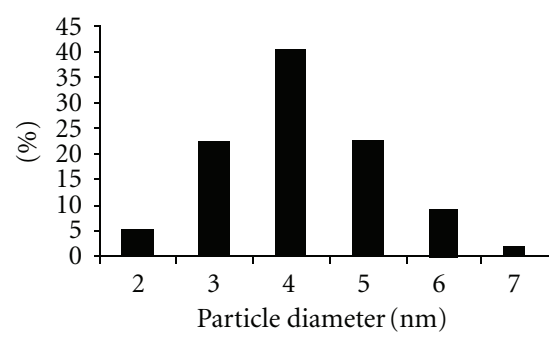

(c) $d=4.6 \pm 1.1 \mathrm{~nm}$

(i)

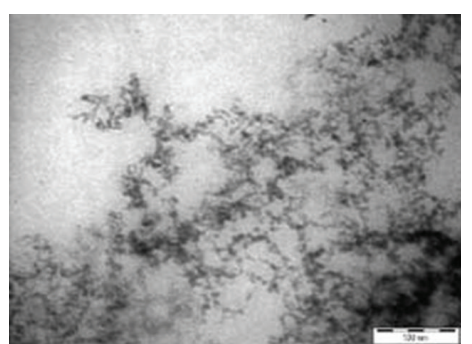

(ii)

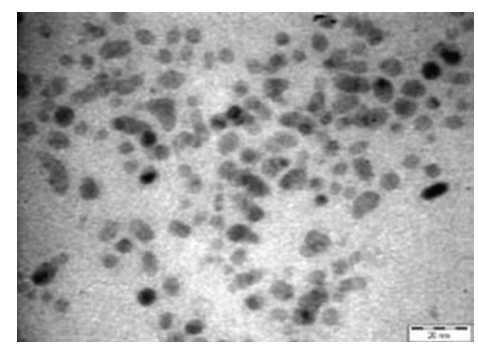

(iii)

Figure 2: TEM micrographs, size distributions of Cu nanoparticles in (a) aqueous phase and organic phase in (b) toluene, and (c) 10\% (v/v) of epoxy-toluene.

the spectrum (Figure 4(a)) shows a broad peak at $3503 \mathrm{~cm}^{-1}$ which is assigned to the stretching vibration of $-\mathrm{OH}$ as well as peaks at 1607,1508 , and $1456 \mathrm{~cm}^{-1}$ are attributed to $\mathrm{C}=\mathrm{C}$ stretching of the aromatic ring [29]. The peak at $915 \mathrm{~cm}^{-1}$ is attributed to oxirane group. On the other hand, the spectrum of MDA (Figure 4(b)) shows peak at $\approx 3400 \mathrm{~cm}^{-1}$ due to the symmetric stretching of $\mathrm{N}-\mathrm{H}$ while peaks at around $3100 \mathrm{~cm}^{-1}$ are due to $\mathrm{C}-\mathrm{H}$ stretching. There were also peaks at 1627,1512 , and $1435 \mathrm{~cm}^{-1}$ as well as $1086 \mathrm{~cm}^{-1}$ that corresponds to the respective $\mathrm{C}=\mathrm{C}$ stretching of the aromatic ring and the $\mathrm{C}-\mathrm{N}$ moiety attached to the aromatic ring. However, the spectra of both of the cured samples (Figures 4(c) and 4(d)) show that the characteristic peak of oxirane has disappeared. Furthermore, the intensity of peak positioned at $\approx 3400 \mathrm{~cm}^{-1}$ and $\approx 1100 \mathrm{~cm}^{-1}$ which corresponds to respective hydroxyl group and $\mathrm{C}-\mathrm{N}$ was increased. Therefore the extent of curing process between the epoxy and amine can be followed via; (i) disappearance of oxirane peak positioned at $915 \mathrm{~cm}^{-1}$ and (ii) the ratio of peak intensity between the $\mathrm{C}-\mathrm{N}$ or $\mathrm{O}-\mathrm{H}$ to the phenyl. The phenyl peak was selected as reference because it is not modified during curing.

The disappearance of oxirane peak is the consequence from MDA addition which causes ring opening of the oxirane and forms cross-linking network during the curing process. A typical epoxy-MDA curing reaction is as shown in Figure 5(a). During the curing process, hydrogens of the amine react with the oxirane of the DGEBA forming hydroxyls and C-N linkages. The newly formed hydroxyl groups also exert autocatalytic role thus promoting further 


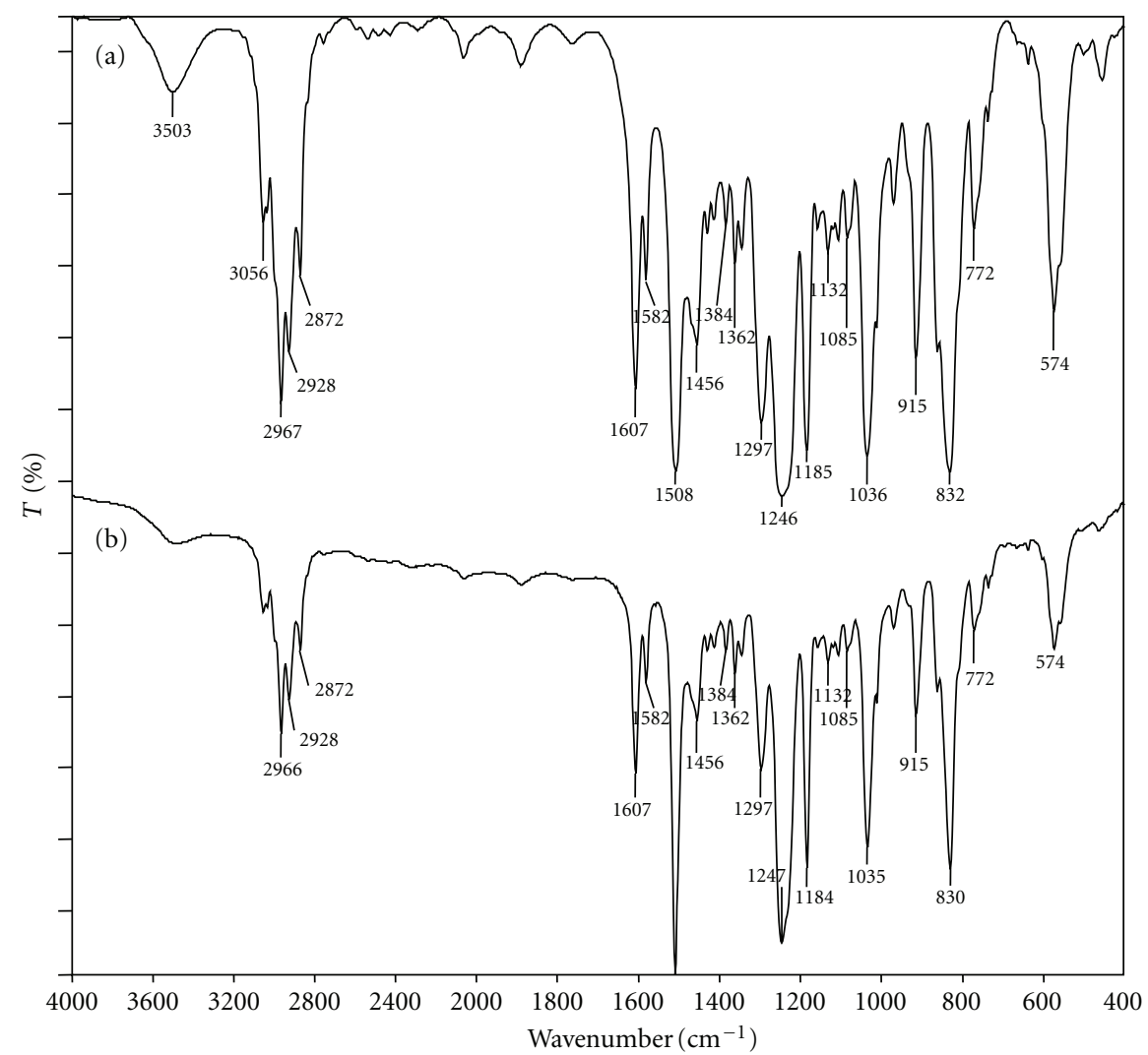

FIGURE 3: FTIR spectra of (a) epoxy and (b) Cu in 10\% (v/v) epoxy/toluene.

oxirane-amine reactions as shown in Figure 5(b) [30]. As reaction proceeds, more of the amine reacted, resulting in disappearance of primary and secondary amine peaks at $\approx 3300 \mathrm{~cm}^{-1}$ and $\approx 3400 \mathrm{~cm}^{-1}$, respectively. As a result, more hydroxyls and $\mathrm{C}-\mathrm{N}$ linkages existed in the cured epoxy and the cured composite as compared to respective neat epoxy, and MDA. This is implicated by an increase in the intensity of peak corresponding to $\mathrm{C}-\mathrm{N}$ and hydroxyls group.

The values of the various ratio of peak intensity for neat epoxy, MDA, cured epoxy and the cured composite are tabulated in Table 2. The results show that the obtained $\mathrm{Abs}_{\mathrm{C}-\mathrm{N}}$ to $\mathrm{Abs}_{\text {phenyl }}$ ratio of pristine MDA is 0.72 . The value is increased to 1.00 and 1.09 for the respective cured epoxy/MDA to the cured $\mathrm{Cu}$-epoxy/MDA. Moreover, there is an increase in the ratio $A b s_{\text {hydroxyl }}$ to $A b s_{\text {phenyl }}$ from 0.55 to 0.72 and 0.75 for the respective neat epoxy, cured epoxy/MDA, and cured $\mathrm{Cu}$-epoxy/MDA. As a result, the curing process is deemed complete due to total disappearance of oxirane peak as well as the increment in ratio of both of $\mathrm{C}-\mathrm{N}$ and $\mathrm{O}-\mathrm{H}$ to the phenyl. The addition of $\mathrm{Cu}$ particles into the epoxy does not seem to affect the curing process even though several works have reported that addition of particles decreases the degree of curing [31,32].

In the cured composite, there is a possible competition between the curing reaction of epoxy-MDA and the complex formation of $\mathrm{Cu}^{2+}$-MDA $[33,34]$. However, in this work, the phenomenon is avoidable as most of the $\mathrm{Cu}^{2+}$ ions remain in the aqueous phase during phase transfer process. Thus, few $\mathrm{Cu}^{2+}$ ions are available for formation of the complex. In addition, the complex formations are more likely to occur at low temperature. Thus at curing temperature, the epoxyamine reaction is favored. The formation of complex in the organosol, if any, will be masked if and when the organosol is subjected to high temperature.

\subsubsection{Thermal Properties}

TG-FTIR Analysis. Figure 6 shows the TG and DTG curves of neat epoxy, epoxy/MDA, and a Cu-epoxy/MDA composite. A summary of the TG and DTG data is tabulated in Table 3. Neat epoxy exhibited two degradation steps. The first degradation step is within $320-370^{\circ} \mathrm{C}$ and is where the major weight loss occurred. The maximum degradation temperature, $T_{\max }$, is at $355^{\circ} \mathrm{C}$. The second degradation step is within $370^{\circ} \mathrm{C}$ to $440^{\circ} \mathrm{C}$. Cured epoxy instead exhibits a small degradation step with $\approx 0.4 \%$ weight loss at around $50-80^{\circ} \mathrm{C}$. It is followed by a major degradation step at a higher temperature compared to neat epoxy that starts at $380^{\circ} \mathrm{C}$ until $435^{\circ} \mathrm{C}$ with a weight loss of $\approx 90.7 \%$ and $T_{\max }$ at $400^{\circ} \mathrm{C}$. The cured $\mathrm{Cu}-$ epoxy/MDA composite with $0.05 \mathrm{vol} \%$ of $\mathrm{Cu}$ filler exhibits a single step degradation at a lower temperature, that is, from $372^{\circ} \mathrm{C}$ to $440^{\circ} \mathrm{C}$ with a weight loss of $\approx 83.4 \%$ and $T_{\max }$ at $410^{\circ} \mathrm{C}$. Increasing the amount of $\mathrm{Cu}$ filler up to 1.0 vol.\% in the composite causes the degradation step to occur from $360^{\circ} \mathrm{C}$ to $432^{\circ} \mathrm{C}$ with a weight loss of $80.6 \%$ and $T_{\max }$ at $385^{\circ} \mathrm{C}$. In both cases, the decrease in the weight loss of 


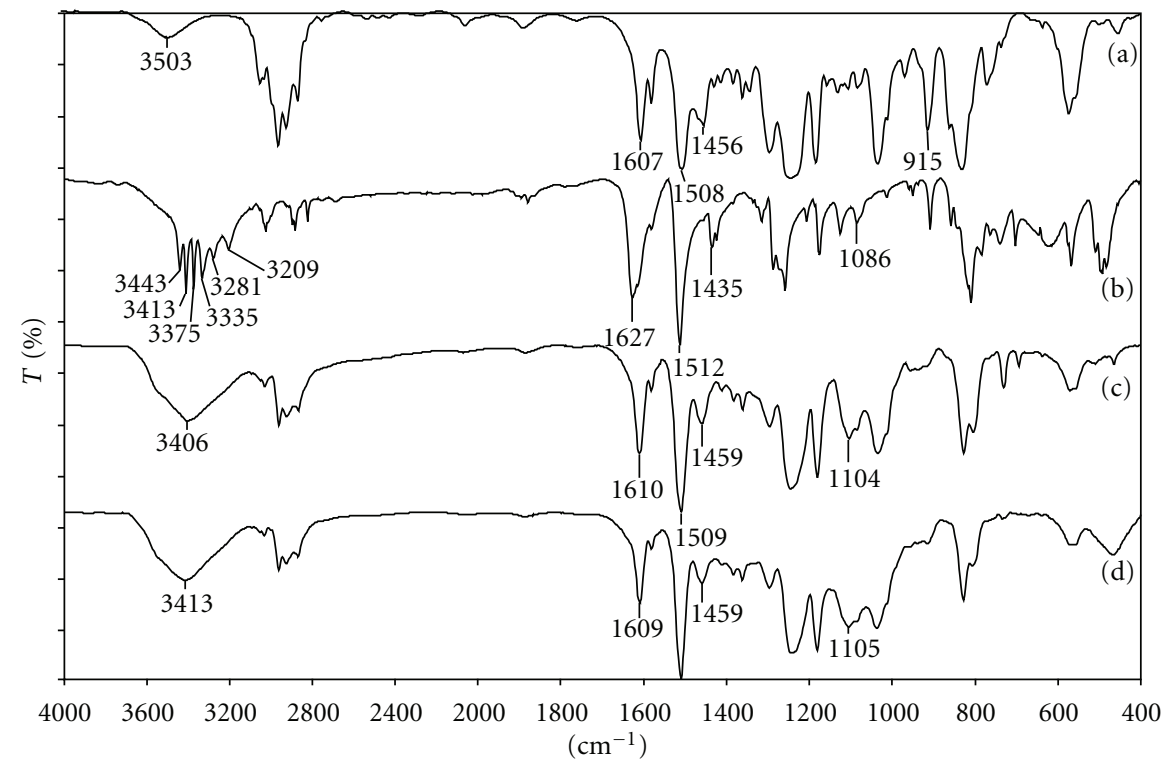

FIgURE 4: FTIR spectra of (a) neat epoxy, (b) MDA, and 10\% (v/v) of (c) cured epoxy/MDA and (d) cured Cu -epoxy/MDA.

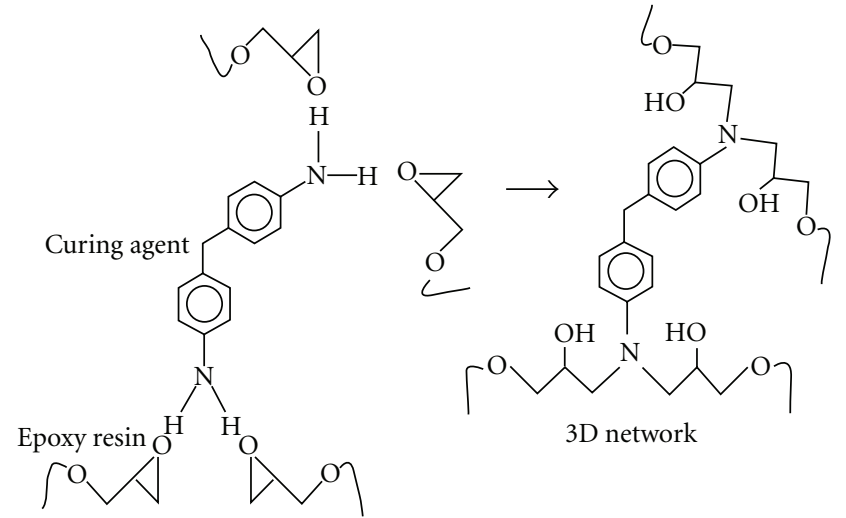

(a)

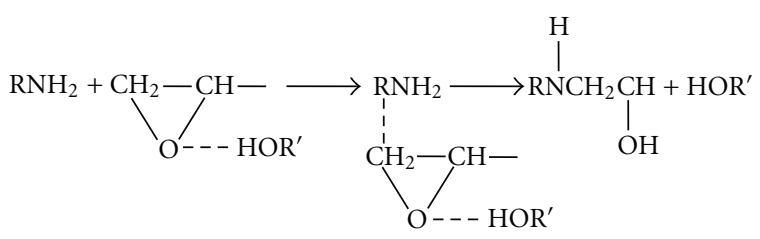

(b)

FIGURE 5: (a) Cross-linking reaction of epoxy with an amine-based curing agent and (b) schematic illustration of autocatalytic role of hydroxyl group.

the composites as compared to cured epoxy or neat epoxy is due to the presence of $\mathrm{Cu}$ filler that promotes degradation.

For the cured epoxy, the small degradation corresponds to traces of moisture trapped within the cured sample while major degradation corresponds to cross-linking in sample which occurs at a much higher temperature compared to neat epoxy. Obviously, the cross-linking reactions between epoxy and MDA have resulted in interlocking structures that provide better thermal stability. This is because bond breaking within cross-linked polymer network requires a large amount of energy [35]. However, addition of $\mathrm{Cu}$ filler slightly decreases the degradation temperature from $380^{\circ} \mathrm{C}$ to $372^{\circ} \mathrm{C}$ as compared to cured epoxy. The presence of $\mathrm{Cu}$ nanoparticles accelerates the composite's thermal transport during decomposition of polymers which will increase the composite's volatilization. This will effectively lower the thermal stability. Increasing the amount of $\mathrm{Cu}$ filler up to 1.0 vol.\% will further accelerate the composite degradation and further reduce its thermal stability. This is also observed by several workers and is probably due to the surface interaction between metal particles and the polymer [36, 37].

The FTIR spectra of the volatiles shown in Figure 7 depict the degradation of neat epoxy and cured analogues of epoxy/MDA and Cu-epoxy/MDA composite. For neat epoxy, peaks positioned between $3600 \mathrm{~cm}^{-1}$ and $4000 \mathrm{~cm}^{-1}$ are attributed to the $\mathrm{O}-\mathrm{H}$ stretching of water vapour [38]. Peaks are also seen to arise between $2800 \mathrm{~cm}^{-1}$ and $3100 \mathrm{~cm}^{-1}$ due to $\mathrm{C}-\mathrm{H}$ stretching [39], $\approx 2300 \mathrm{~cm}^{-1}$ corresponding to carbon dioxide [38], $1600 \mathrm{~cm}^{-1}$ and $1500 \mathrm{~cm}^{-1}$ attributed to aromatic $\mathrm{C}-\mathrm{H}[40]$, and $\approx 1200 \mathrm{~cm}^{-1}$ due to asymmetric stretching of the $\mathrm{C}-\mathrm{O}-\mathrm{C}$ ethers. Furthermore, peaks at $\approx 800 \mathrm{~cm}^{-1}$ and $\approx 1000 \mathrm{~cm}^{-1}$ are due to $\mathrm{C}-\mathrm{H}$ of para-disubstitution of phenyl rings and stretching of aryl-O- $\mathrm{CH}_{2}$, respectively. However epoxy/MDA shows similar peaks except for disappearance of peak positioned at $\approx 1000 \mathrm{~cm}^{-1}$ as well as an addition of peak positioned at $\approx 700 \mathrm{~cm}^{-1}$. The former is due to the different preference of chain scission of the cured network while the later is attributed to $\mathrm{C}-\mathrm{H}$ of meta-disubstitution of phenyl rings originated from MDA. It is observed that the spectra of $\mathrm{Cu}$-epoxy/MDA composite exhibit similar peaks. This indicates that similar volatile products were produced during the degradation process. This is probably due to the existence of physical interactions instead of chemical interactions between the $\mathrm{Cu}$ filler and 
TABLE 2: Absorbance of C-N $\left(\approx 1100 \mathrm{~cm}^{-1}\right)$, benzene $\left(\approx 1608 \mathrm{~cm}^{-1}\right)$, hydroxyl $\left(3200 \mathrm{~cm}^{-1}\right)$, oxirane $\left(915 \mathrm{~cm}^{-1}\right)$, and the respective peak ratios of hydroxyl and oxirane to benzene.

\begin{tabular}{|c|c|c|c|c|c|c|c|c|}
\hline & $\mathrm{C}-\mathrm{N}$ & $\begin{array}{l}\text { Benzene } \\
\text { ring }\end{array}$ & $\begin{array}{l}\text { Hydroxyl } \\
\text { group }\end{array}$ & $\begin{array}{l}\text { Oxirane } \\
\text { group }\end{array}$ & $\begin{array}{c}\text { Ratio } \\
\text { (OH/ } \\
\text { benzene) }\end{array}$ & $\begin{array}{c}\text { Ratio } \\
\text { (Oxirane/ } \\
\text { benzene) }\end{array}$ & $\begin{array}{c}\text { Ratio } \\
\text { (C-N/benzene) }\end{array}$ & $\begin{array}{l}\text { Spectrum in } \\
\text { Figure } 4\end{array}$ \\
\hline Neat epoxy & - & 85 & 47 & 82 & 0.55 & 0.96 & - & (a) \\
\hline $\mathrm{MDA}$ & 48 & 67 & - & - & - & - & 0.72 & (b) \\
\hline Cured epoxy/MDA & 69 & 69 & 50 & - & 0.72 & - & 1.00 & (c) \\
\hline $\begin{array}{l}\text { Cured Cu with } \\
\text { epoxy/MDA }\end{array}$ & 61 & 56 & 42 & - & 0.75 & - & 1.09 & (d) \\
\hline
\end{tabular}

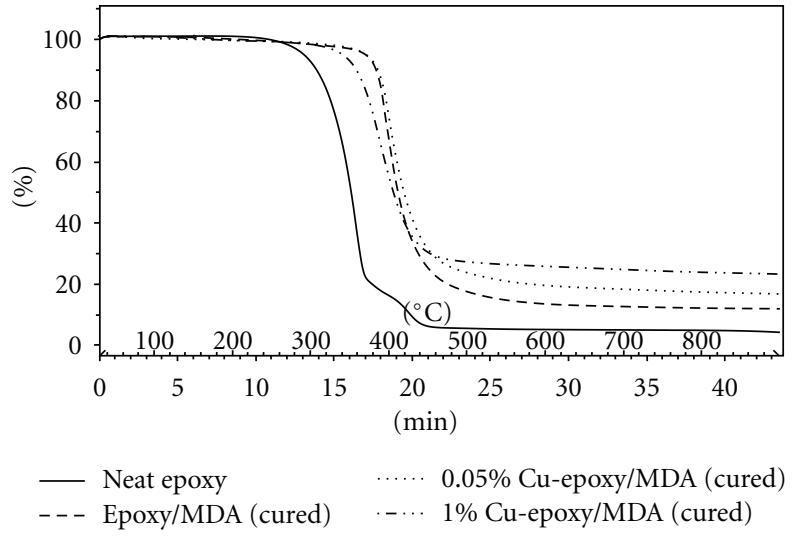

(a)

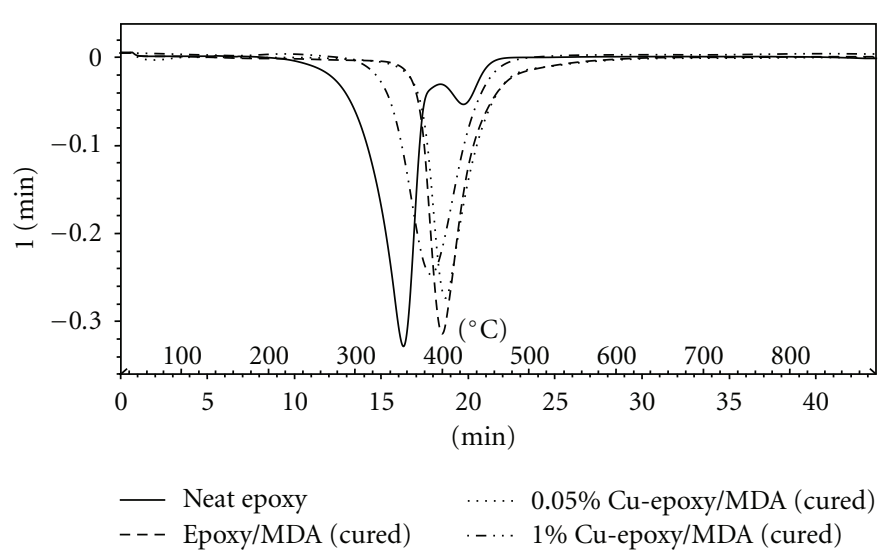

(b)

FIgURe 6: (a) TG and (b) DTG curves of neat epoxy, epoxy/MDA, and Cu-epoxy/MDA samples.

the polymer matrix. Therefore addition of $\mathrm{Cu}$ filler does not affect the overall mechanism of the degradation of the composites. Lee [41] has proposed that degradation of epoxy resin comprised of several schemes made up from degradation of main chain via heterolytic cleavage of bisphenol A and homolytic scission and cyclization of the side group. These produced several smaller volatile products such as isopropylphenol, ethylphenol, cresol, phenol, and ether derivatives.

DSC Analysis. The melting peaks of $\mathrm{Cu}$ nanoparticles are not observed in all the DSC traces. $T_{g}$ of all samples is tabulated in Table 3. The $T_{g}$ of pure epoxy is $-12.1^{\circ} \mathrm{C}$. In cured epoxy, cross-linked networks resulted in a decrease in free volume of polymer and restricted polymer chain mobility. This resulted in a higher $T_{g}$ value of $114.9^{\circ} \mathrm{C}$. The presence of $0.05 \mathrm{vol} . \%$ $\mathrm{Cu}$ particles in the cured composite caused a further increase in the $T_{g}$ value to $122.7^{\circ} \mathrm{C}$. Increasing the amount of $\mathrm{Cu}$ to 1.0 vol. \% in the composite slightly increases this value to $123.4^{\circ} \mathrm{C}$. This behavior shows that further addition of $\mathrm{Cu}$ does not affect any significant changes towards the composite as a result from weak physical interactions between the epoxy and $\mathrm{Cu}$ particles. This corresponds to the FTIR results discussed in Section 3.1.2. Furthermore, relatively small particle surface-to-surface distance which has been observed in TEM images can also restrict chain segmental movement.

The DSC results also infer that Cu-MDA complexation does not occur during the curing process. This is because complexation of metal-amine would result in an incomplete curing process due to insufficient amine. This would have caused the resultant composite to exhibit a lower $T_{g}$ value when compared to cured epoxy/MDA, which was not observed in this work.

Coefficient of Thermal Expansion (CTE). The inherently high CTE of polymer is undesirable for applications as thermal packaging where true thermal stability is important. Addition of metallic filler to a polymer matrix is expected to lower the CTE of the resultant composite. The CTE of cured epoxy/MDA and cured $\mathrm{Cu}$-epoxy/MDA composite is tabulated in Table 3. The CTE of cured epoxy/MDA is 87.7 and $155.0 \mathrm{ppm}^{\circ} \mathrm{C}^{-1}$ before and after $T_{g}$, respectively. The inclusion of $\mathrm{Cu}$ filler in the composite reduced the respective CTE values to 76.8 and $146.0 \mathrm{ppm}{ }^{\circ} \mathrm{C}^{-1}$ before and after $T_{g}$. This is $\approx 12 \%$ and $\approx 6 \%$ lower than the unfilled cured epoxy. However, further increase in the loading of $\mathrm{Cu}$ filler in the composite increases the CTE value both before and after $T_{g}$ to 102.8 and $172.2 \mathrm{ppm}^{\circ} \mathrm{C}^{-1}$. Addition of $\mathrm{Cu}$ filler restraints the movement of polymer and increased the packing density within the matrix, therefore preventing it from expanding [42]. However, upon further addition of $\mathrm{Cu}$ particles, the particles may have migrated and formed aggregates in the polymer matrix during the curing process [43]. This may contribute to the reverse effect of the phenomenon discussed previously. It can also be seen that for both samples, the CTE values after $T_{g}$ are much higher than before $T_{g}$. In rubbery 
TABLE 3: Thermal properties of pure epoxy, epoxy/MDA, and Cu-epoxy/MDA samples.

\begin{tabular}{|c|c|c|c|c|c|c|c|}
\hline & \multicolumn{2}{|c|}{ TGA } & \multirow{2}{*}{$\begin{array}{c}\text { DTG } \\
T_{\max }\left({ }^{\circ} \mathrm{C}\right)\end{array}$} & \multirow{2}{*}{$\begin{array}{c}\text { DSC } \\
T_{g}\left({ }^{\circ} \mathrm{C}\right)\end{array}$} & \multicolumn{2}{|c|}{ CTE } \\
\hline & & $\begin{array}{c}\text { Degradation } \\
\text { temperature } \\
\text { range }\left({ }^{\circ} \mathrm{C}\right)\end{array}$ & Weight loss (\%) & & & $\begin{array}{l}\text { Before } T_{g} \\
\left(\mathrm{ppm} /{ }^{\circ} \mathrm{C}\right)\end{array}$ & $\begin{array}{c}\text { After } T_{g} \\
\left(\mathrm{ppm} /{ }^{\circ} \mathrm{C}\right)\end{array}$ \\
\hline Pure epoxy & & $\begin{array}{l}320-370 \\
370-440\end{array}$ & $\begin{array}{l}85.6 \\
12.7\end{array}$ & 355 & -12.1 & - & - \\
\hline Cured epoxy/MDA & & $380-435$ & 90.7 & 400 & 114.9 & 87.7 & 155.0 \\
\hline \multirow{2}{*}{ Cured Cu-epoxy/MDA } & 0.05 vol. $\%$ & $372-440$ & 83.4 & 410 & 122.7 & 76.8 & 146.0 \\
\hline & 1.00 vol. $\%$ & $360-432$ & 80.6 & 385 & 123.4 & 102.9 & 161.3 \\
\hline
\end{tabular}

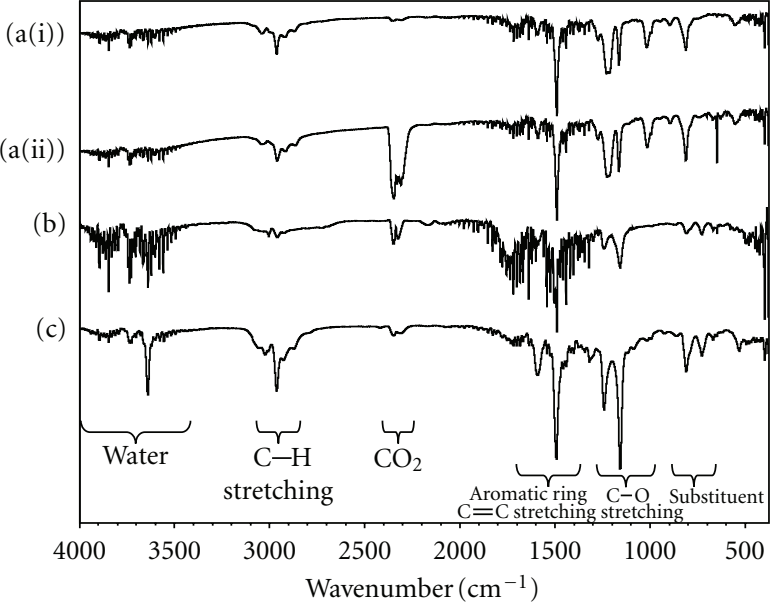

FIGURE 7: TGA/FTIR spectra of (a) epoxy for (i) first degradation (ii) second degradation, (b) Epoxy/MDA, and (c) Cu-Epoxy/MDA.

state (after $T_{g}$ ), the polymer molecules posses higher energy, therefore greater freedom of movement as compared to the glassy state (before $T_{g}$ ). Hence, the polymer molecules will have higher free volume and this imposes material expansion [44].

3.2.3. Electrical Conductivity Profile. At room temperature, conductivity of bulk $\mathrm{Cu}$ is $5.8 \times 10^{5} \mathrm{~S} \mathrm{~cm}^{-1}$ [10]. Figure 8 shows the plot of the conductivity of the composites as a function of $\mathrm{Cu}$ volume fraction. In general, the composites showed lower conductivity than bulk $\mathrm{Cu}$. The addition of $\mathrm{Cu}$ increased the conductivity when compared to the conductivity of cured epoxy which is $2.98 \times 10^{-12} \mathrm{~S} \mathrm{~cm}^{-1}$. Increasing the amount of $\mathrm{Cu}$ filler from 0.1 vol.\% to 1.0 vol.\% shows an increase in the conductivity from $1.46 \times 10^{-2} \mathrm{~S} \mathrm{~cm}^{-1}$ to $3.06 \times 10^{-2} \mathrm{~S} \mathrm{~cm}^{-1}$, respectively. However, upon further addition of $\mathrm{Cu}$ filler up to 5.0 vol.\%, the conductivity value decreases to $1.98 \times 10^{-2} \mathrm{~S} \mathrm{~cm}^{-1}$.

The increase in conductivity in the composites might be due to changes in contact resistance (amount of filler's surface in contact with other fillers in a conductive system) and tunneling resistance (amount of overlapped electron wave function of fillers). In the former, increasing the amount of filler increases the chances of contact area between the fillers. The enhancement in contact area will provide a

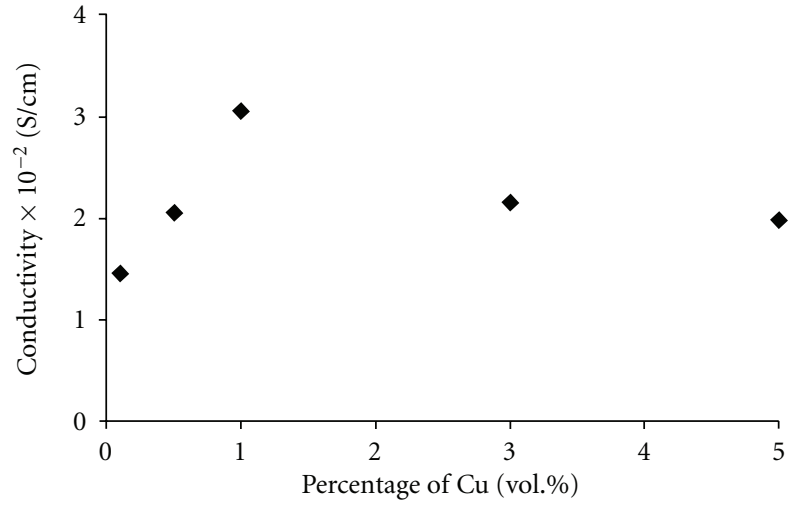

FIGURE 8: Electrical conductivity of Cu-epoxy nanocomposite as a function of volume fractions of $\mathrm{Cu}$.

better conduction path for the electron(s). In the latter case, increasing the amount of filler will reduce the spaces between fillers. Thus within close spaces, electron wave functions of particles overlap each other [45]. This is possible because the distance between particles is small where in this work the average center to center interparticle spacing is $\approx 5 \mathrm{~nm}$. This facilitates electron transfer between the $\mathrm{Cu}$ particles. The decrease in conductivity at higher filler loading may be due to the agglomerate of metal particles that resulted in isolated clusters of particles. This will reduce the number of effective conducting path within the composite.

The conductivity value obtained in this work is higher than some of the values reported in previous works. For instance, 1 to 15 vol.\% Ag-epoxy nanocomposites with electrical conductivities of $10^{-14}$ to $10^{-9} \mathrm{~S} \mathrm{~cm}^{-1}$ were reported by Gonon and Boudefel [13] while Chan et al. [10] obtained an electrical conductivity of $7.65 \times 10^{-3} \mathrm{~S} \mathrm{~cm}^{-1}$ for 5 vol. $\% \mathrm{Cu}-$ epoxy composite.

\section{Conclusion}

The synthesis of $\mathrm{Cu}$ nanoparticles has been achieved by the reduction of cupric acetate with $\mathrm{NaBH}_{4}$. Both CTAB and IPA served as the stabilizing and transferring agent, respectively. The transfer efficiency of the metal particles is $\approx 95 \%$. TEM analysis shows that addition of epoxy and MDA plays a role in controlling size and dispersion of the $\mathrm{Cu}$ nanoparticles. The noninteractions between the epoxy/MDA in organic phase 
with $\mathrm{Cu}$ is certified by FTIR analyses. A slight decrement of the thermal stability is observed for Cu-epoxy/MDA composite compared to the cured unfilled epoxy/MDA. Nonetheless, it is above $300^{\circ} \mathrm{C}$. The composites also exhibit conducting properties comparable to Ag-epoxy nanocomposites. Thus, the $\mathrm{Cu}$-epoxy composites prepared by aqueous to organic phase transfer method afforded acceptable thermal properties and comparable electrical conductivity as to other composites reported previously.

\section{Acknowledgments}

The authors would like to thank INTEL Technology (M) Sdn Bhd (Grant no. 304/PKIMIA/650341/I104) and Universiti Sains Malaysia (Grant no. 1001/PKIMIA/831005 and 1001/PKIMIA/811091) for the financial assistance granted to this project and the USM Fellowship awarded to N. H. M. Hirmizi.

\section{References}

[1] M. Sánchez-Soto, P. Pagés, T. Lacorte, K. Briceño, and F. Carrasco, "Curing FTIR study and mechanical characterization of glass bead filled trifunctional epoxy composites," Composites Science and Technology, vol. 67, no. 9, pp. 1974-1985, 2007.

[2] H. Chen, O. Jacobs, W. Wu, G. Rüdiger, and B. Schädel, "Effect of dispersion method on tribological properties of carbon nanotube reinforced epoxy resin composites," Polymer Testing, vol. 26, no. 3, pp. 351-360, 2007.

[3] H. P. Wu, X. J. Wu, M. Y. Ge, G. Q. Zhang, Y. W. Wang, and J. Z. Jiang, "Effect analysis of filler sizes on percolation threshold of isotropical conductive adhesives," Composites Science and Technology, vol. 67, no. 6, pp. 1116-1120, 2007.

[4] H. Jiang, K. S. Moon, J. Lu, and C. P. Wong, "Conductivity enhancement of nano silver-filled conductive adhesives by particle surface functionalization," Journal of Electronic Materials, vol. 34, no. 11, pp. 1432-1439, 2005.

[5] F. Tan, X. Qiao, J. Chen, and H. Wang, "Effects of coupling agents on the properties of epoxy-based electrically conductive adhesives," International Journal of Adhesion and Adhesives, vol. 26, no. 6, pp. 406-413, 2006.

[6] H. P. Wu, J. F. Liu, X. J. Wu et al., "High conductivity of isotropic conductive adhesives filled with silver nanowires," International Journal of Adhesion and Adhesives, vol. 26, no. 8, pp. 617-621, 2006.

[7] I. Pardiñas-Blanco, C. E. Hoppe, M. A. López-Quintela, and J. Rivas, "Control on the dispersion of gold nanoparticles in an epoxy network," Journal of Non-Crystalline Solids, vol. 353, no. 8-10, pp. 826-828, 2007.

[8] C. F. Goh, H. Yu, S. S. Yong, S. G. Mhaisalkar, F. Y. C. Boey, and P. S. Teo, "Synthesis and cure kinetics of isotropic conductive adhesives comprising sub-micrometer sized nickel particles," Materials Science and Engineering B, vol. 117, no. 2, pp. 153158, 2005.

[9] R. Kahraman, M. Sunar, and B. Yilbas, "Influence of adhesive thickness and filler content on the mechanical performance of aluminum single-lap joints bonded with aluminum powder filled epoxy adhesive," Journal of Materials Processing Technology, vol. 205, no. 1-3, pp. 183-189, 2008.

[10] K. L. Chan, M. Mariatti, Z. Lockman, and L. C. Sim, "Effect of ultrasonication medium on the properties of copper nanoparticle-filled epoxy composite for electrical conductive adhesive (ECA) application," Journal of Materials Science, vol. 21, no. 8, pp. 772-778, 2010.

[11] X. Zhang, X. Cheng, H. Yin, J. Yuan, and C. Xu, "Preparation of needle shaped nano-copper by microwave-assisted water system and study on its application of enhanced epoxy resin coating electrical conductivity," Applied Surface Science, vol. 254, no. 18, pp. 5757-5759, 2008.

[12] D. I. Tee, M. Mariatti, A. Azizan, C. H. See, and K. F. Chong, "Effect of silane-based coupling agent on the properties of silver nanoparticles filled epoxy composites," Composites Science and Technology, vol. 67, no. 11-12, pp. 2584-2591, 2007.

[13] P. Gonon and A. Boudefel, "Electrical properties of epoxy/ silver nanocomposites," Journal of Applied Physics, vol. 99, no. 2, Article ID 024308, pp. 1-8, 2006.

[14] Y. Yagci, M. Sangermano, and G. Rizza, "Synthesis and characterization of gold-epoxy nanocomposites by visible light photoinduced electron transfer and cationic polymerization processes," Macromolecules, vol. 41, no. 20, pp. 7268-7270, 2008.

[15] M. Sastry, "Phase transfer protocols in nanoparticle synthesis," Current Science, vol. 85, no. 12, pp. 1735-1745, 2003.

[16] M. Sastry, A. Kumar, and P. Mukherjee, "Phase transfer of aqueous colloidal gold particles into organic solutions containing fatty amine molecules," Colloids and Surfaces A, vol. 181, no. 1-3, pp. 255-259, 2001.

[17] T. Bala, A. Swami, B. L. V. Prasad, and M. Sastry, "Phase transfer of oleic acid capped $\mathrm{Ni}_{\text {core }} \mathrm{Ag}_{\text {shell }}$ nanoparticles assisted by the flexibility of oleic acid on the surface of silver," Journal of Colloid and Interface Science, vol. 283, no. 2, pp. 422-431, 2005.

[18] D. G. Li, S. H. Chen, S. Y. Zhao, X. M. Hou, H. Y. Ma, and X. G. Yang, "A study of phase transfer processes of Ag nanoparticles," Applied Surface Science, vol. 200, no. 1-4, pp. 62-67, 2002.

[19] L. M. Liz-Marzán and A. P. Philipse, "Stable hydrosols of metallic and bimetallic nanoparticles immobilized on imogolite fibers," Journal of Physical Chemistry, vol. 99, no. 41, pp. 15120-15128, 1995.

[20] Z. M. Sui, X. Chen, L. Y. Wang et al., "Capping effect of CTAB on positively charged Ag nanoparticles," Physica E, vol. 33, no. 2, pp. 308-314, 2006.

[21] B. Nikoobakht and M. A. El-Sayed, "Evidence for bilayer assembly of cationic surfactants on the surface of gold nanorods," Langmuir, vol. 17, no. 20, pp. 6368-6374, 2001.

[22] J. Yang, J. Y. Lee, and H. P. Too, "A general phase transfer protocol for synthesizing alkylamine-stabilized nanoparticles of noble metals," Analytica Chimica Acta, vol. 588, no. 1, pp. 34-41, 2007.

[23] A. A. Athawale, P. P. Katre, M. Kumar, and M. B. Majumdar, "Synthesis of CTAB-IPA reduced copper nanoparticles," Materials Chemistry and Physics, vol. 91, no. 2-3, pp. 507-512, 2005.

[24] Y. Zhang, S. Wang, X. Li, L. Chen, Y. Qian, and Z. Zhang, "CuO shuttle-like nanocrystals synthesized by oriented attachment," Journal of Crystal Growth, vol. 291, no. 1, pp. 196-201, 2006.

[25] N. Gao, J. Dong, H. Zhang, X. Zhou, G. Zhang, and J. Eastoe, "Application of a multi-dentate amphiphilic compound to transfer silver nanoparticles into an organic solvent," Journal of Colloid and Interface Science, vol. 304, no. 2, pp. 388-393, 2006.

[26] S. Underwood and P. Mulvaney, "Effect of the solution refractive index on the color of gold colloids," Langmuir, vol. 10, no. 10, pp. 3427-3430, 1994.

[27] N. R. Jana, Z. L. Wang, T. K. Sau, and T. Pal, "Seed-mediated growth method to prepare cubic copper nanoparticles," Current Science, vol. 79, no. 9, pp. 1367-1370, 2000. 
[28] S. Panigrahi, S. Kundu, S. K. Ghosh et al., "Selective one-pot synthesis of copper nanorods under surfactantless condition," Polyhedron, vol. 25, no. 5, pp. 1263-1269, 2006.

[29] R. C. M. Sales, M. F. Diniz, R. C. L. Dutra, G. P. Thim, and D. Dibbern-Brunelli, "Study of curing process of glass fiber and epoxy resin composite by FT-NIR, photoacoustic spectroscopy and luminescence spectroscopy," Journal of Materials Science, vol. 46, no. 6, pp. 1814-1823, 2011.

[30] J. Y. Lee, M. J. Shim, and S. W. Kim, "Effect of modified rubber compound on the cure kinetics of DGEBA/MDA system by Kissinger and isoconversional methods," Thermochimica Acta, vol. 371, no. 1-2, pp. 45-51, 2001.

[31] K. Tao, S. Yang, J. C. Grunlan et al., "Effects of carbon nanotube fillers on the curing processes of epoxy resin-based composites," Journal of Applied Polymer Science, vol. 102, no. 6, pp. 5248-5254, 2006.

[32] M. R. Loos, L. A. F. Coelho, S. H. Pezzin, and S. C. Amico, "Effect of carbon nanotubes addition on the mechanical and thermal properties of epoxy matrices," Materials Research, vol. 11, no. 3, pp. 347-352, 2008.

[33] M. Aufray and A. André Roche, "Epoxy-amine/metal interphases: influences from sharp needle-like crystal formation," International Journal of Adhesion and Adhesives, vol. 27, no. 5, pp. 387-393, 2007.

[34] M. Aufray and A. A. Roche, "Properties of the interphase epoxy-amine/metal: influences from the nature of the amine and the metal," in Adhesion-Current Research and Applications, pp. 89-102, Wiley-VCH, New York, NY, USA, 2005.

[35] C. A. Gracia-Fernández, S. Gómez-Barreiro, S. Ruíz-Salvador, and R. Blaine, "Study of the degradation of a thermoset system using TGA and modulated TGA," Progress in Organic Coatings, vol. 54, no. 4, pp. 332-336, 2005.

[36] S. Y. Yeo, W. L. Tan, M. Abu Bakar, and J. Ismail, "Silver sulfide/poly(3-hydroxybutyrate) nanocomposites: thermal stability and kinetic analysis of thermal degradation," Polymer Degradation and Stability, vol. 95, no. 8, pp. 1299-1304, 2010.

[37] L. M. Gorghiu, S. Jipa, T. Zaharescu, R. Setnescu, and I. Mihalcea, "The effect of metals on thermal degradation of polyethylenes," Polymer Degradation and Stability, vol. 84, no. 1, pp. 7-11, 2004.

[38] L. Jie, L. Yuwen, S. Jingyan et al., "The investigation of thermal decomposition pathways of phenylalanine and tyrosine by TG-FTIR," Thermochimica Acta, vol. 467, no. 1-2, pp. 20-29, 2008.

[39] K. Pielichowski and K. Flejtuch, "Non-oxidative thermal degradation of poly(ethylene oxide): kinetic and thermoanalytical study," Journal of Analytical and Applied Pyrolysis, vol. 73, no. 1, pp. 131-138, 2005.

[40] D. Rosu, L. Rosu, and M. Brebu, "Thermal stability of silver sulfathiazole-epoxy resin network," Journal of Analytical and Applied Pyrolysis, vol. 92, no. 1, pp. 10-18, 2011.

[41] L. H. Lee, "Mechanisms of thermal degradation of phenolic condensation polymers. II. Thermal stability and degradation schemes of epoxy resins," Journal of Polymer Science Part A, vol. 3, no. 3, pp. 859-882, 1965.

[42] F. N. Ahmad, M. Jaafar, S. Palaniandy, and K. A. M. Azizli, "Effect of particle shape of silica mineral on the properties of epoxy composites," Composites Science and Technology, vol. 68, no. 2, pp. 346-353, 2008.

[43] M. Rong, M. Zhang, H. Liu, and H. Zeng, "Synthesis of silver nanoparticles and their self-organization behavior in epoxy resin," Polymer, vol. 40, no. 22, pp. 6169-6178, 1999.

[44] E. S. A. Rashid, K. Ariffin, C. C. Kooi, and H. M. Akil, "Preparation and properties of POSS/epoxy composites for electronic packaging applications," Materials and Design, vol. 30, no. 1, pp. 1-8, 2009.

[45] X. Yuan, C. Li, G. Guan, Y. Xiao, and D. Zhang, "Thermal degradation investigation of poly(ethylene terephthalate)/fibrous silicate nanocomposites," Polymer Degradation and Stability, vol. 93, no. 2, pp. 466-475, 2008. 

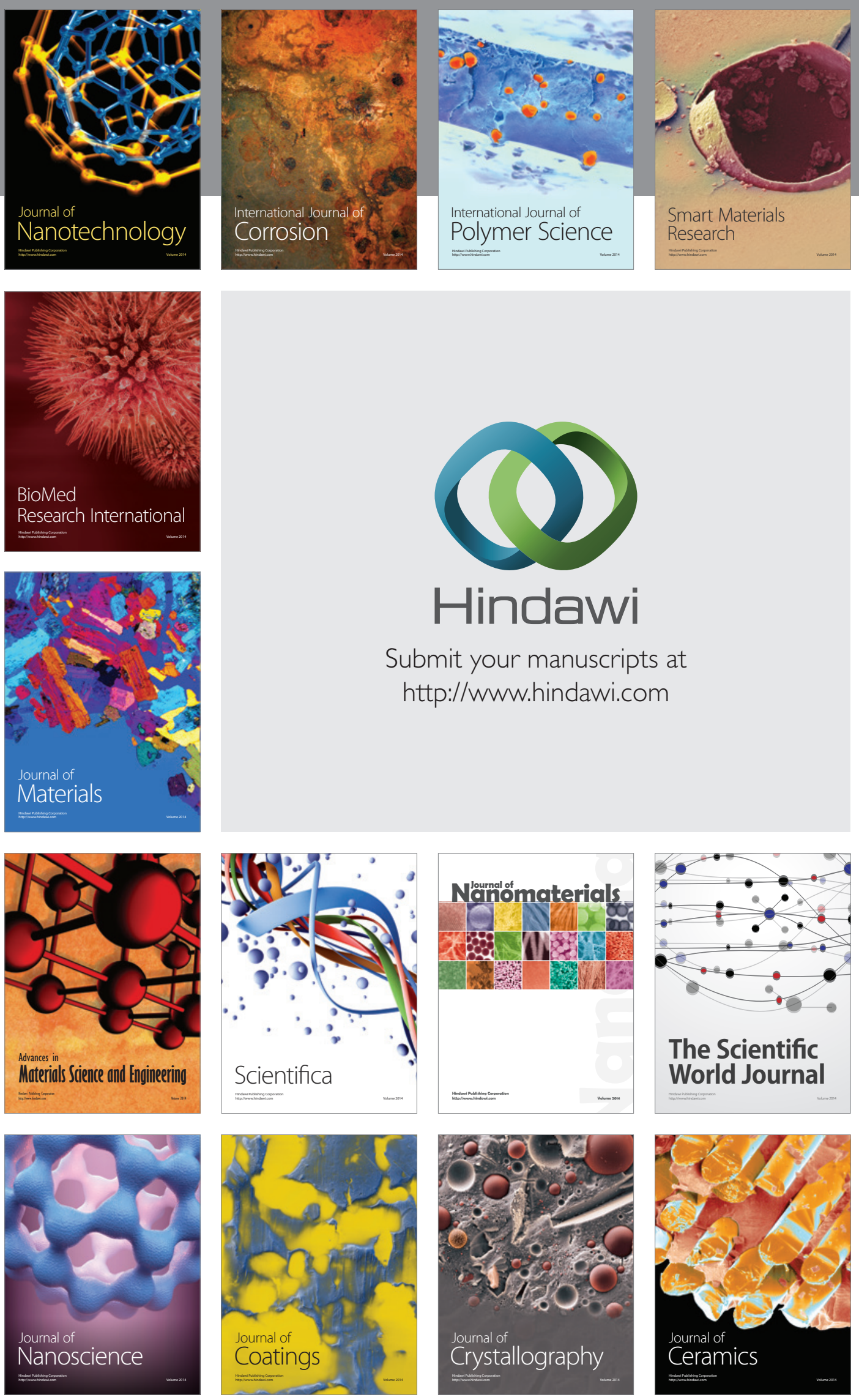

The Scientific World Journal

Submit your manuscripts at

http://www.hindawi.com

\section{World Journal}

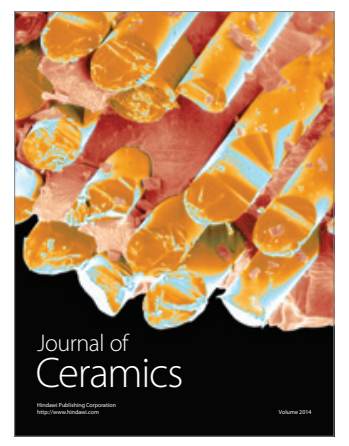

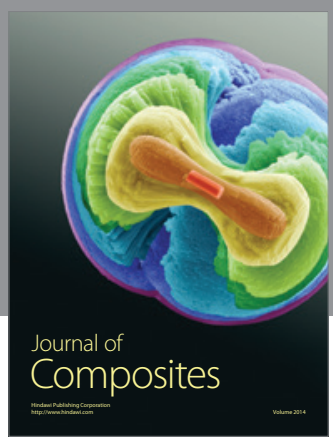
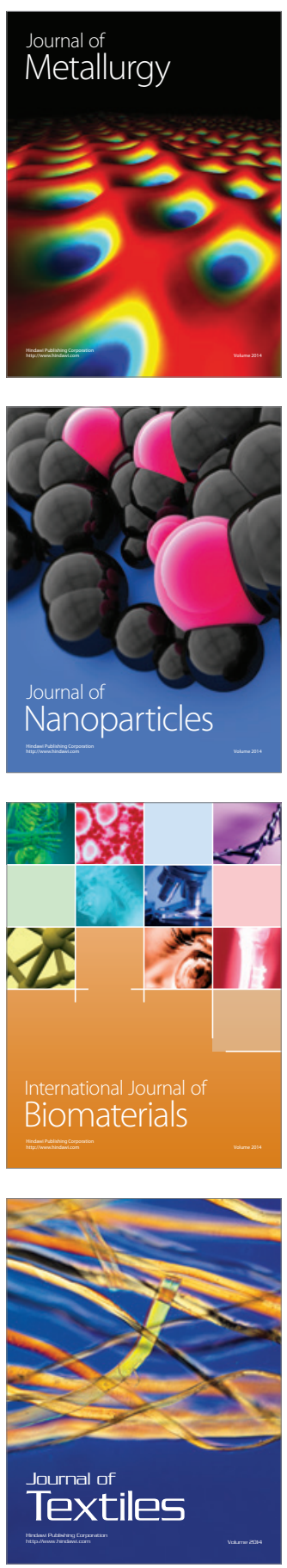